\title{
Perihilar Bile Duct Cancer pTis TNM
}

\section{Finding v8}

National Cancer Institute

\section{Source}

National Cancer Institute. Perihilar Bile Duct Cancer pT is TNM Finding v8. NCI Thesaurus. Code C134724.

Perihilar bile duct cancer with a finding of carcinoma in situ/high grade dysplasia. (from AJCC 8th Ed.) 